\title{
College English Curriculum Group: The Construction Based on Needs Analysis
}

\author{
Jianfeng Zhang ${ }^{1}$ \\ ${ }^{1}$ College of Humanities and Foreign Languages, Xi' an University of Science and Technology, China \\ Correspondence: Jianfeng Zhang, College of Humanities and Foreign Languages, Xi'an University of Science \\ and Technology, Lintong District, Xi'an city, Shaanxi Province, China. Tel: 86-180-669-771-27. E-mail: \\ zhangjianfeng091024@126.com
}

\author{
Received: April 10, 2018 Accepted: May 12, 2018 Online Published: May 14, 2018 \\ doi: 10.5539/elt.v11n6p80 URL: http://doi.org/10.5539/elt.v11n6p80
}

\begin{abstract}
The rapid development of society and economy is not only the opportunity but also the challenge of the college English teaching in China. Nowadays, traditional college English curriculum, with its monotonous content and musty teaching principles, can hardly activate learners' motivation, because the curriculum design neglects learners' needs. Therefore, instrument, humanity and profession should be integrated in English education and college English curriculum group has been designed and constructed. In this curriculum system, based on the learners' needs analysis, EGP and ESP are combined; and on the Internet platform that makes use of educational resources, a new mode of English Instruction, "online teaching + traditional teaching + autonomous inquiry + discussion", has been explored; the comprehensive assessment system and reasonable teacher structures are designed so that learners' motivation can be activated and the practical ability of foreign language can be improved significantly.
\end{abstract}

Keywords: college English, curriculum group, needs analysis

\section{Introduction}

The college English instruction in China has made remarkable achievements in the cultivation of learners' language expression and application since 1980's, but serious problems still exist in the teaching and learning, such as unclear personnel training objective, monotonous content and musty teaching principles. The main reason is to neglect learners' needs; therefore, the direction of college English teaching reform has caused wide concern of Chinese academia. In response to this reason, based on learning needs analysis that combines the English for General Purpose (EGP) with English for Specific Purpose (ESP) and on the Internet platform that makes use of "Internet + educational resources" (Chen et al., 2016), college English curriculum group has been designed and constructed; moreover, a new mode of evaluation system has been explored to form the comprehensive curriculum system and educational program, which it is of great significance to the strategy of strengthening the nation on talents.

\section{Literature Review}

\subsection{Curriculum Group}

Based on the modern educational concepts and a variety of advanced instructional technology platform, curriculum group refers to a unified planning, redesigning and reconstructive curriculum system, whose courses are mutual influence and dependence in the instruction (Wang et al., 2001). Therefore, every course in the curriculum group is not chaotic but a comprehensive, uniform, orderly and efficient system, which is grounded on rational design, scientific mechanism and overall talents educating targets. Nowadays, the curriculum design decides and influences the achievement of talents training goals to a great extent. The reform and design of a certain course cannot meet the needs of comprehensive high-quality talents. So constructing scientific, rational and efficient curriculum group that can strengthen the integration between disciplines and make use of group superiority is very crucial to the reform of higher education in China and is conductive to improving teaching quality, highlighting characteristics.

The Ministry of Education of Chinese Republic of China issued College English Curriculum Requirements in July, 2007, which clearly mentioned that college English teaching in China must take into account 
instrumentality and humanity. Since then, college English teaching has not been a traditional course which simply instructed words, sentences and grammar. At present, it should be a kind of multivariate, applied, cultural and comprehensive curriculum group, which can assist learners to learn about the whole world and broaden knowledge. Meanwhile, the curriculum group of college English is different from traditional courses and should rearrange the syllabus and reconsider teaching content based on the learners' needs; moreover, according to different teaching methods in different courses, this curriculum group should increase the learners' enthusiasm for foreign language learning and satisfy the needs of social development and international communication so that college students in China can become high-level-compound talents from the professional, application, skill and culture.

\subsection{Needs Analysis}

Needs analysis are largely used in the field of language curriculum design for it determines the content and aims of the curriculum being designed. There are various levels of needs. Hutchinson and Waters (1987) put forward learning-cantered approach and differentiated between learning needs and target needs in English language learning. They stressed that learners' needs should be based on the target situation, so the needs can be divided into three segments: lacks, necessities and wants. Dudley and St. John's model (1998) consisted of 7 factors: learners' needs, wants, skills, competencies, lacks, learners' cognitive style and learning preferences. Jordan (1997) argued that teachers and curriculum designers should have their own purposes, priorities, needs, strategies and constrains. In China, Xia (1999) is the first scholar who introduced the concept of needs analysis into English curriculum design. Chen (2009) reviewed the achievements of overseas need analysis and appraised the several influential models. Nowadays, needs analysis is mainly used in ESP.

Therefore, learners' needs analysis is not only the base of curriculum group building, but also the precondition of teaching planning making, learning material selecting and teaching evaluation carrying. Without scientific and systematic needs analysis, every course in the group will be unclear in objectives and roles so that the content of teaching may be overlapping or missing.

\section{3 "Internet + Education"}

The concept of "Internet +" represents a new form of society that Internet (including mobile communication, cloud computing, big data, etc.) will integrate and apply with traditional economy and industries, providing a vast platform for innovation and reform ( $\mathrm{Li}$ et al., 2017). As the core of information technology, Internet has been deeply integrated with all kinds of industries. When confronting with education, it is rapidly reforming and reconstructing the whole educational industry, which is changing the organization mode and rebuilding eco-system of education.

In the information repository of the Internet, the resources that directly serve education are inexhaustible. Learners can choose what they want and need at anytime and anywhere via network terminal. Therefore, Internet + education will help to change the manner of teaching and learning; learners can dynamically select according to their own needs; in addition, teachers are likely to adjust teaching methods as well as material and to provide pertinent guidance based on scientific and precise learning about learners' status, preference and demands.

Therefore, to change the current situation of college English teaching in China and meet the learners' learning needs, this paper will construct a college English curriculum group, which is based on the Internet platform and combines EGP and ESP closely; meanwhile, assessment index and system will be further explored so that the teaching performance can be improved efficiently.

\section{Construction of College English Curriculum Group}

\subsection{Needs Analysis of Chinese Learners}

The construction of curriculum group should base on the dynamic changes of learners' needs. According to the theories of needs analysis and learning motivation, Chinese English learners' needs can be divided into two parts: one is the needs of performance goal orientation, whose learners mainly focus on the improvement of grades and the acquirement of various certificates. For these needs, the criteria are the improvement of basic language skills and the avoidance of mistakes or errors in foreign language learning; the other is the needs of mastery goal orientation, whose leaners are mainly focus on the improvement of competence and the fulfilment of tasks. For these needs, leaners pay close attention to whether English learning can help them accomplish the tasks of specialized courses learning and meet the standards of social acknowledgement (Zhang, 2014). Therefore, performance goal orientation and mastery goal orientation should be considered when college English curriculum group is constructed. 


\subsection{College English Curriculum Group}

Based on learners' learning needs analysis, college English curriculum group is constructed as is shown in Figure 1.

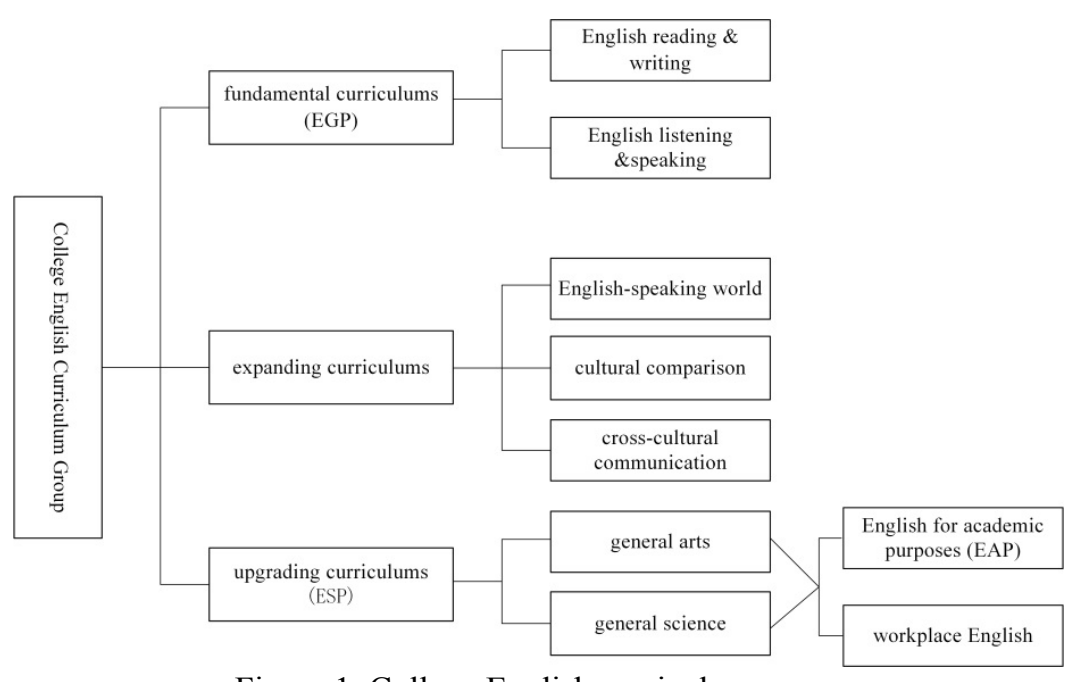

Figure 1. College English curriculum group

\subsubsection{Curriculum Setting}

College English curriculum group can be divided into three levels: fundamental curriculums, expanding curriculums and upgrading curriculums. In the first and second semesters, based on Internet and Web, fundamental curriculums are set, including traditional English reading, writing, listening and speaking (EGP curriculums), which will bridge between college and high school and help learners to adapt the environment of college English learning as well as promoting their basic language skills. In this level, curriculum setting can meet the needs of performance goal orientation and lay a language foundation for the further teaching and learning.

In the third semester, relying on fundamental English curriculums, expanding curriculums are set in the form of Mooc and micro-class video, including the introduction to the English-speaking world, comparison between Chinese and western cultures and cross-cultural communication etc. In this level, learners can freely select courses according to their interests and needs, acquiring basic humanistic knowledge.

In the fourth semester, based on reinforcement of language learning, upgrading curriculums (ESP curriculums) are set. According to the different background of liberal arts and science, courses are separated from general arts and general science, offering EAP courses and workplace English respectively, which can meet the needs of mastery goal orientation.

In this college English curriculum group, three levels of course are taught in blocks, but at the time these courses are coordinated, supported, inter-infiltrated and inter-promoted, satisfying the needs of different levels for selective learning according to their actual needs.

\subsubsection{Teaching Content}

The teaching content of fundamental curriculums relies on EGP, which mainly focuses on the training of basic language skills. Curriculums include traditional English reading, writing, phonetics, listening and speaking. Based on the emotional characteristics of contemporary college students, language materials that are close to college life are elaborately chosen. Meanwhile, a web-based multi-learning environment can be built via interaction of classroom, QQ or WeChat group. The teaching content mainly helps learners to promote their English level and lays a solid foundation for the next step.

The teaching content of expanding curriculums consists of the brief introduction of English-speaking countries, cross-cultural communication and the comparison between China and west in history, culture, politics and society. These contents are more likely to attract learners to learn English and to stimulate their learning motivation, which are not only beneficial to improve basic language skills, but also to cultivate learners' 
humanistic quality, critical thinking so that it is of great necessity to increase their inter-cultural communication competence and is the connection and transition between EGP and ESP.

The teaching content of upgrading curriculum is ESP and designed by learners' learning needs and their professional backgrounds, including history, literature, business English, technical English, mechanical English, computer English, architectural English, biological English, chemical English and so on. In this level, the teaching content aims at fostering learners' ability to learn professional knowledge based on the platform of English and fully developing the instrumental and practical English such as attending a lecture, participation of discussion, reading professional journals, the ability to write term papers in English. All courses can be presented in the form of Moocs or micro-class video; besides, teaching material can be stored in kinds of mobile teaching systems to realize the individuality and autonomy of English learning and to meet the needs of different learning goal orientation and different professional background.

\subsection{Teaching Mode}

In recent years, the information technology represented by Internet has constantly led the social change, improved humans' capacity to recognize and transform the world. The rapid development of Internet has promoted the optimization and innovation of all professions and trades; what's more, the ecology of "Internet +" is gradually forming. Based on the full understanding of the great roles of Internet technology in social life, Chinese government issued "Guidelines on the 'Internet +' Campaign" in July, 2015, which mentioned 11 action plans on the "internet +". For education, the concept of "Internet + education" has been proposed and it is required to explore the new educational service supply modes on Internet as the infrastructure and original element. The "Internet + education" is not only the opportunity but also the challenge of the college English instruction in China. Therefore, relying on multimedia teaching facilities and Web system, a new mode of college English teaching, "online teaching + traditional teaching + autonomous inquiry + discussion", is constructed via joint development of teachers and learners' efforts, which is showed in Figure 2.

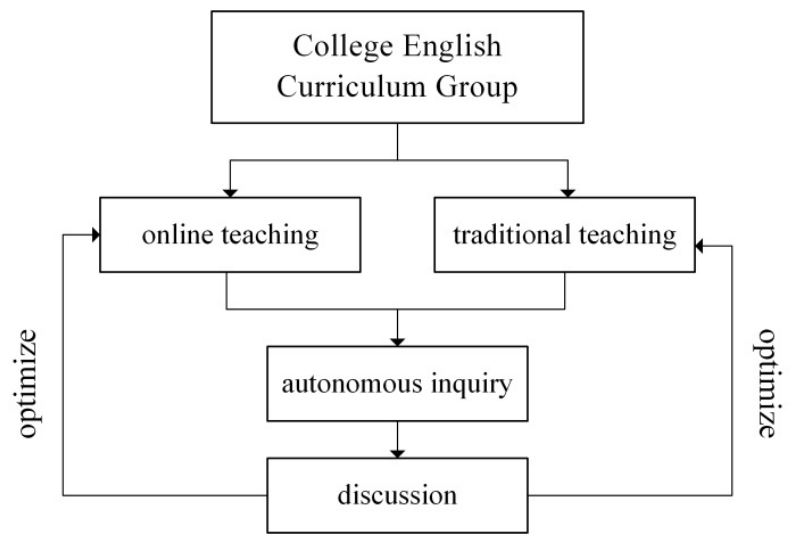

Figure 2. College English teaching mode

\subsubsection{Online Teaching}

Every course in the college English curriculum group will be developed online course, Mooc, micro-class video or mobile phone class. In addition, teachers can use micro blog, QQ or WeChat group to guide learners in organizing learning plans, adjusting learning progress and finishing the assignments or quizzes. Therefore, the time and space of teaching can be constantly extended and the interaction between teachers and students or students and students can be fully realized to avoid learners' passive acceptance or rote learning so that the effective outputs of language learning can be acquired. Besides, online teaching provides targeted language teaching services and large-scale individualized learning according learners' needs and characteristics; big data can record and analyse every student' learning records to assist him or her improving learning efficiency via "one to one" teaching service so that learning needs of different levels will be met.

\subsubsection{Traditional Teaching}

In the traditional teaching mode, teachers explain new words; introduce background of text; analyse reading skills and discriminate long and difficult sentences according to the syllabus or teaching planning. Meanwhile, students are asked to take notes and to finish the assignments on time. Assignments are divided into two parts: 
one is the written homework, which students must finish exercises and acquire corresponding words or grammar; the other is the assignments of analysis and discussion, which students must search for material according to teachers' requirements and assimilate what they have learned.

\subsubsection{Autonomous Inquiry}

"Internet + education" makes college English teaching more independent, personalized and data-oriented, so autonomous learning and inquiry learning have become increasingly popular. Based on the campus network and digital library, students can develop autonomous inquiry. In this process, learners make their own learning plans, choose their own methods to read, observe and consider so that they can propose their own hypothesis and seek for answers. Simultaneously, students absorb and assimilate knowledge through autonomous exploration and construction of new schemata. In addition, for openness and non-linear nature of Internet, there are many channels for learners' autonomous inquiry and they have sufficient time and space to think or explore freely so that their knowledge construction will be changed continuously and their enthusiasm to learn English can be aroused. The learning efficiency will be successfully promoted as well.

After autonomous inquiry, learners are divided into several teams to discuss their findings according to their inquiry based on online teaching and traditional teaching. Each team prepares for speech outline and selects representatives to make presentation. Teachers will summarize and comment on these presentation and analyse or answer the common questions and confusion. Meanwhile, teachers will optimize the teaching process according to learners' feedback and prepare for the new teaching content.

\subsection{Assessment}

A comprehensive assessment system is needed in college English curriculum. In this system, the relationship between each curriculum should be considered and the outcome of curriculums should be focused on as well; at the same time, external evaluation is very important and internal examination should be stressed too. Therefore, the assessment system can evaluate the whole curriculum scientifically and form a fusion mechanism combining the content of each course assessment and the content of common assessment. Not only can the overall English assessment requirements of the same level be reflected, but also the characteristics of each course can be highlighted so that the grades balance of students who take part in different course can be guaranteed.

Besides, in terms of assessment of each course, the evaluation consists of teacher, leaners and team, which is shown in Figure 3. Teacher evaluates learners via final exam to form summative assessment; teacher, learners and team can get formative assessment through the object's class performance, capacity of autonomous learning and participation of discussion; final results can be obtained by combining these two assessments. In the assessment system, the subjects of evaluation are teacher, learners and team, so the results are more balanced and objective. For teacher, he or she can judge the teaching performance based on the results and adjust or optimize the teaching process if necessary; for employers, they can focus on different assessments based on the requirements of post. This assessment system can make comprehensive evaluation of all aspects and monitor the whole teaching process.

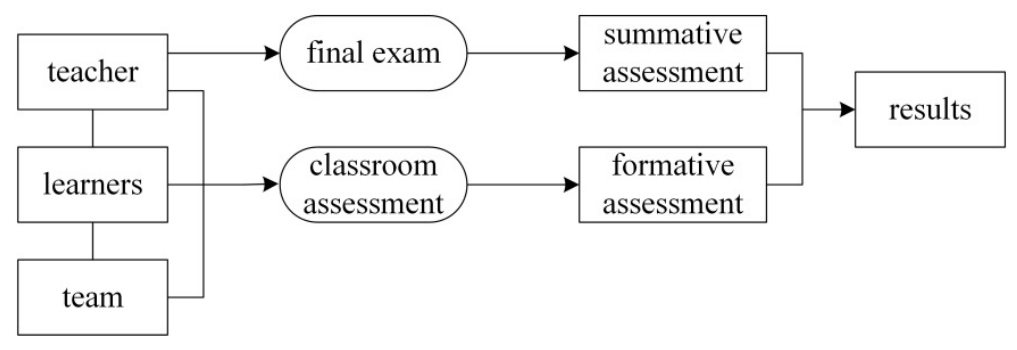

Figure 3. Assessment system

\subsection{Teacher Structure}

The construction of college English curriculum group will challenge teaching methods, teaching concepts and teachers' roles. It needs to cultivate a group of professional and specialized teachers who are familiar with Internet technology and can take on EGP and ESP teaching. Teachers are the soul of education so it is necessary condition to foster and reserve excellent teaching staff and to construct and form ideal pattern of the echelon. 
On one hand, traditional teaching tasks allocation mechanism, which a teacher teach a class from freshmen year to sophomore year and then from freshmen year again, must be broken and form more stable courses distribution. Teachers can select their favourite courses according to their professional background, knowledge reserve, interests and their teaching characteristics. This pattern can help teachers to improve teaching performance and it is beneficial for them to accumulate high-quality teaching resources to develop and build online courses gradually.

On the other hand, course teaching team consists of academic leader and outstanding young teachers. Academic leader is responsible for teaching methods reform and teaching arrangement to guarantee the teaching quality of each course; young teachers support the teaching of each course and need to establish "famous band of course".

\section{Conclusion}

Based on learners' needs analysis and aiming at innovation and application, college English curriculum group need integrate technology and resources constantly to solve severe problems that exist in college English teaching so that the its roles can be greatly promoted in Chinese higher educations. Besides, with the further development of the reform of English teaching and the promotion of basic education course, college English curriculum group which combine EGP and ESP can unify instrumental, humanistic and professional foreign language learning gradually so that learners' learning interest can be stimulated and improve their foreign language comprehensive practice ability.

\section{Acknowledgement}

This study is sponsored by the Instructional Research Project (JG16070) of Xi'an University of Science and Technology.

\section{References}

Chen, B. B. (2009). Review of Needs Analysis. Foreign Language Teaching and Research, 41(2), 125-130.

Chen, L., Lin, S. Y., \& Zheng, Q. H. (2016). Opportunities and Challenges of Chinese Distance Education in the "Internet +" Era. Modern Distance Education Research, 139(1), 3-10.

Dudley, T., \& St. John. (1998). Developments in English for Specific Purposes: A multi-disciplinary approach. Cambridge University Press, Cambridge.

Hutchinson, T., \& Waters, A. (1987). English for Specific Purposes. Cambridge University Press, Cambridge. https://doi.org/10.1017/CBO9780511733031

Jordan, R. R. (1997). English for academic purposes: A guide and resource book for teachers. Cambridge: Cambridge University Press. https://doi.org/10.1017/CBO9780511733062

Li, D. R., Shen, X., \& Chen, N. C. (2017). Space-based information service in Internet Plus Era. Sci. China Inf. Sci., 60(10), 1-10. https://doi.org/10.1007/s11432-016-9164-1

Wang, J. C., \& Yang, S. Y. (2001). On the Research and Practice of the Construction of Course-grouping. Journal of Beijing Institute of Technology (Social Science Edition), 3(2), 71-86.

Xia, J. M. (1999). A Preliminary Study on the Design of Foreign Language Courses. Foreign Language World, 73(1), 26-31.

Zhang, J. F. (2014). Chinese Students' Goal Orientation in English Learning: A Study Based on Autonomous Inquiry Model. English Language Teaching, 7(2), 84-89. https://doi.org/10.5539/elt.v7n2p84

\section{Copyrights}

Copyright for this article is retained by the author(s), with first publication rights granted to the journal.

This is an open-access article distributed under the terms and conditions of the Creative Commons Attribution license (http://creativecommons.org/licenses/by/4.0/). 